\title{
円形断面光導波路のテーパ接合部における 電磁界の等角写像による考察
}

\author{
正員宮 崎 保光 (豊橋技術科学大学) \\ Analysis of Electromagnetic Field at Tapered Junction of Optical Circular Waveguides Using Conformal Mapping \\ Yasumitsu Miyazaki,Member(Toyohashi University of Technology)
}

\begin{abstract}
Tapered couplers between optical fibers, and laser diodes or integrated circuits are very important components for optical communication and optical signal processing. Mode matching at the tapered junction of optical circular waveguide is required to obtain high efficiency and low loss in optical circuits. In this paper, electromagnetic fields in tapered couplers with the inhomogeneous refractive index are investigated for general optical waveguides with arbitrary cross sections. The optimum designs for tapered shape and inhomogeneous refractive index in matching coupler are found by the integral equations using conformal mapping. This method has been developped by the author for the analysis of the complicated millimeter waveguides. Electromagnetic mode conversions and reflections in axial symmetric circular tapered couplers are discussed by integral equations with Green's dyadics and conformall mapping.
\end{abstract}

キーワード : 等角写像, Green関数, テーパ光遒波路

\section{1. まえがき}

半導体レーザの出力光は, 横長のビームモードから正方 形に近い矩形モードに近くなりつつあるが，シングルモー ド光ファイバあるいは多モード光ファイバとの結合におい ては, モ一ド整合が十分行われていない1-3)。また, 半導体 レーザと光集積回路, 光ファイバと光集積回路においても 同様なモード整合の課題が残されている4-7)。これまで，マ イクロレンズあるいは, ファイバ端面加工によって, モー ド整合が試みられているが, 効率のよい結合は行われてい ない。本論文では，モード分布が一般的形状をもつ2つの 固有伀送系間を効率よく，モード整合をとることが可能な， テ一パ状の屈折率分布型導波路結合素子についての電磁界 特性を明らかにし，効率の高いモード結合素子の最適設計 を与える理論を示している。とくに, 等角写像と積分方程式 により一般的境界形状と一般的屈折率分布をもつテーパ状 屈折率分布型導波の電磁界の蕨密な解析法を展開している。

境界が複雑な電磁界の境界値問題の解法にはモード展開 法を中心に, 各種の解析的手法と数值計算法が用いられて いる。筆者らは，1964年にミリ波導波管の折れ曲り部にお ける入射 $T E_{01}$ 波のモード変換と反射の 3 次元問題におい て, 等角写像法とGreen 関数を用いた積分方程式法が有効 であることを示した ${ }^{8)}$ 。1965年には，だ円筒の散乱，回折 をはじめ，等角写像法と濑近展開法の組合せ法も有効であ ることを示した9)。その後曲がり導波管，曲がりビーム波導 波路について検討し，1972 年には光ファイバと光ICの導波
路設計について等角写像とGreen 関数を用いた積分方程式 法の一般理論を示した ${ }^{10-12) 。 ~}$

近年では，半導体レーザと光IC導波路，不均質テーパ 導波路を用いた光分波器について等角写像法を展開した 13-14)。また, EMC 問題としてマイクロ波, 高周波フィル ター設計についても有用性を示した15)。

ここでは，具体的数值例を求めるのに基本的性質を有す る回転対称界のテーパ部における電磁界解析について等角 写像と Green 関数を用いた積分方程式法による手法を示し， 最適設計，反射，モード変換，放射界について示す。

\section{2. テーパ部における等角写像}

円筒形状導波路と円錐形導波路の接合問題は，これまで， モード展開法などにより検討されてきている導波路の境界 值問題として，座標系，モード系の異なる領域の接合問題 として基本的な課題である。

筆者らは，これまで，ウェジによる漸近界に基づいた回 折手法により円形 $\mathrm{TE}_{01}$ モードと円錐 $\mathrm{TE}$ モードの反射モー ド変換を示した16)。ここでは，ゆるやかな接合であるテー パ部の電磁界を等角写像と Green 関数を用いて積分方程式 法によって検討する。図 1 は，一般的断面をもつテーパ導 波路であり，図2 は円形断面をもつ軸対称なテーパ導波路 である。

図 3 に示すように，害空間の $(X, Y, Z),(R, \theta, Z)$ におけ るテーパ導波路を $(R, Z)$ 平面についての等角写像により， 
図 4 の写像空間 $(r, \theta, z)$ における真直な遧波路に写像する ことを考える。

テーパ形状および複雑な横断面をもつ屈折率分布型導波 路における電磁界の解析は, 標準的な, 厳密な解が得られ る導波路からの摄動として, 等角写像による解析に示され る。ここで，基準形および摄動形の分布に対し，(1),(2)の 記号を用いて，

$$
\begin{array}{ll}
\text { コアの誘電率が } & \varepsilon_{1}=\varepsilon_{1}^{(1)}+\varepsilon_{1}^{(2)} \\
\text { クラッドの誘電率が } & \varepsilon_{2}=\varepsilon_{2}^{(1)}+\varepsilon_{2}^{(2)}
\end{array}
$$

である。テーパ導波路が $(X, Y, Z)$ 空間内に存在していると き，標準型境界をもつ導波路一の写像を考える。写像にお ける測度 $h$ は, 線素 $d s^{2}$ につて

$$
\begin{aligned}
d s^{2} & =d X^{2}+d Y^{2}+d Z^{2} \\
& =h_{x}^{2} d x^{2}+h_{y}^{2} d y^{2}+h_{z}^{2} d z^{2} .
\end{aligned}
$$

ここで,

$$
\begin{aligned}
& d X^{2}+d Y^{2}=h_{1}^{2}\left(d x^{2}+d y^{2}\right) \\
& d X^{2}+d Z^{2}=h_{2}^{2}\left(d x^{2}+d z^{2}\right) \\
& d Y^{2}+d Z^{2}=h_{3}^{2}\left(d y^{2}+d z^{2}\right)
\end{aligned}
$$

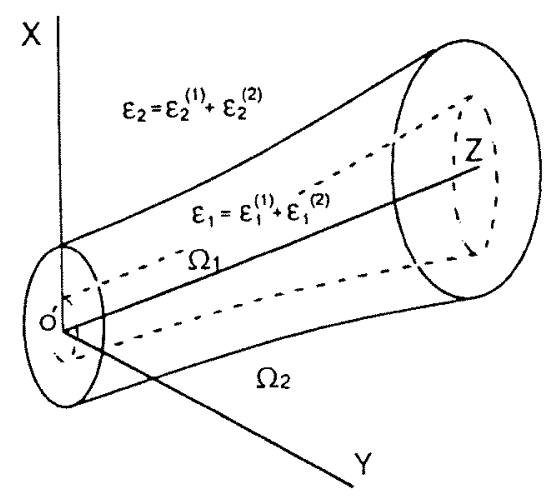

図 1.テーパ状屈折率分布型導波路

Fig.1 Tapered waveguide of the dielectric distribution

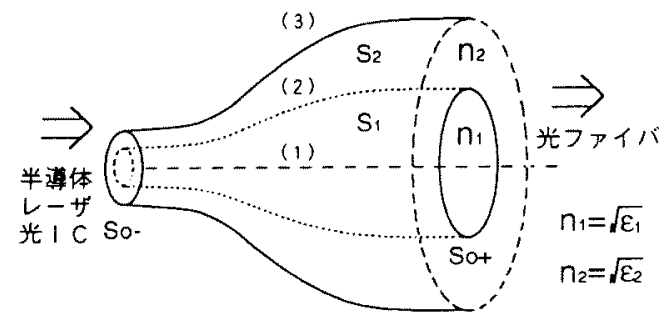

図 2.円形断面光導波路のテーパ部

Fig.2 Tapered part of circular sectional optical waveguide また, 複素面 $Z_{i}$ と複素面 $z_{i}$ について，

$$
\begin{array}{ll}
\dot{Z}_{1}=X+j Y, & \dot{z}_{1}=x+j y \\
\dot{Z}_{2}=X+j Z, & \dot{z}_{2}=x+j z \\
\dot{Z}_{3}=Y+j Z, & \dot{z}_{3}=y+j z
\end{array}
$$

とすれば，測度係数 $h_{i}$ は，

$$
h_{i}=\left|\frac{d \dot{Z}}{d \dot{z}}\right|
$$

で与えられる。

横断面に接しては，Riemanの写像定理によれば， $Z_{1}$ 平面 上で連続体を境界とする単連結領域 $D$ を平面 $z_{1}$ の単位円に 写像することができる。このときの写像は，

$$
\dot{Z}=\sum a_{n} \dot{z}^{n}
$$

によって与えられる。

テーパ部においては，たとえば

$$
\dot{Z}=\dot{z}+\frac{a}{c} \tan ^{-1} c z
$$

によって与えられる。ここに, $(Z, X)$ 平面と $(z, x)$ 平面では

$$
\dot{Z}=Z+j X, \quad \dot{z}=z+j x
$$

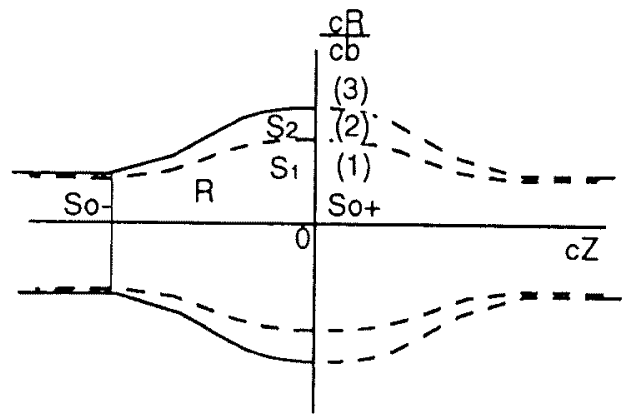

図 3．実空間におけるテーパ導波路

Fig.3 Tapered waveguide in real space

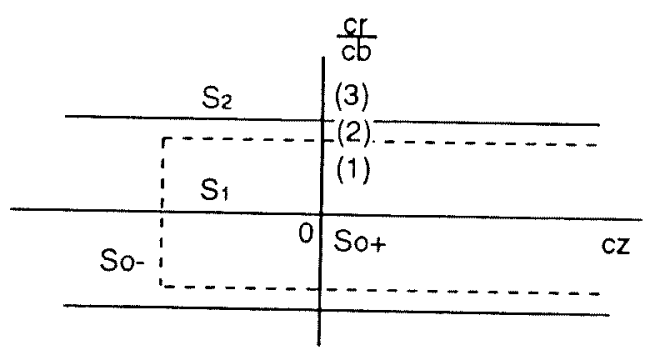

図 4，写像空間におけるテーパ導波路

Fig.4 Tapered waveguide in mapping space

ここでは，図3に示される軸対称のテーパ部における電磁 界について考える。直楾偏波の光モードは，2つの円偏波 光モードの合成によって示される。多くの場合，直線偏波に 近い $\mathrm{HE}_{11}$ モードが入射されるため，ここでは，円偏波の対 称モードについて基本的性質を検討するにとどめる。図 5 (a)におけるテーパ部において，物理空間としての寒空間を 


$$
\dot{Z}=Z+j R
$$

として考える。 $\dot{Z}$ 空間を，図 5 (b)に示す $\dot{z}$ 空間に写像する。 $\dot{z}$

$$
\dot{z}=z+j r
$$

テーパ部の解析に用いる等角写像は

$$
\dot{Z}=\dot{z}+\frac{a}{c} \tan ^{-1} c \dot{z}
$$

また， $a, c$ は凸形境界のパラメータである。光ファイバの境 界は $\operatorname{Im}(\dot{z})=|r|=b$, 光ファイバの最大径は, $(R, \theta, Z)$ 空 間において， $Z=0$ において $2 R=(1+a) 2 b$ であ。空間 の測度係数は

$$
h=\left|\frac{d \dot{Z}}{d \dot{z}}\right|=\left|1+\frac{a}{1+(c \dot{z})^{2}}\right|
$$

$Z=0$ 近くにおける境界では,

$$
\begin{aligned}
R & =(1+a) r\left\{1-\frac{a}{1+a}\left(\frac{c Z}{1+a}\right)^{2}\right\}+\cdots \\
& =(1+a) r(1+s(r, z)) \cdots \cdots \cdots \cdots \cdots
\end{aligned}
$$

$(1+a) r=r_{1}, r_{1} s=s_{1}$ とすれば，

$$
R=r_{1}+s_{1}(r, z)
$$

また，座標 $(Z, R)$ と座標 $(z, r)$ につては，一般に

$$
\begin{aligned}
& Z=z+\frac{a}{2 c} \tan ^{-1} \frac{2 c z}{1-(c z)^{2}-(c r)^{2}} \\
& R=r+\frac{a}{2 c} \tanh ^{-1} \frac{2 c r}{1+(c z)^{2}+(c r)^{2}}
\end{aligned}
$$

さらに，測度パラメータ $h$ につて，中心軸近傍では

$$
h^{2}=(1+a)^{2}\left(1-l_{z}^{2} z^{2}\right)+g
$$

$$
\text { ここに, }
$$

$$
l_{x}=\frac{2 a c^{2}}{1+a}
$$

$$
\begin{aligned}
g= & (1+a)\left\{2 a c^{2} r^{2}\right. \\
& \left.-a c^{4}\left[\left(r^{2}+z^{2}\right)^{2}-4\left(z^{2}-r^{2}\right)^{2}\right]\right\}+\cdots
\end{aligned}
$$

また，中心軸の周辺では，

$$
\begin{aligned}
& h^{2}=(1+a)^{2}\left(d-l_{z}^{2} z^{2}\right)+f \\
& d=1+\frac{a\left(2 c^{2} b^{2}+3 c^{4} b^{4}\right)}{1+a} \ldots \\
& l_{z}^{2}=\frac{2 a c^{2}}{1+a}+8 \frac{a c^{4} b^{2}}{1+a} \cdots
\end{aligned}
$$

ここに,

$$
\begin{aligned}
f= & (1+a) a\left[(|r|-b)\left(16 c^{4} b z^{2}-4 c^{2} b-12 b^{3} c^{4}\right)\right. \\
& +(|r|-b)^{2}\left(2 c^{2}-8 c^{4} z^{2}+18 b^{2} c^{4}\right) \\
& \left.+(|r|-b)^{3}\left(-12 b c^{4}\right)+(|r|-b)^{4} 3 c^{4}\right] \\
& +\cdots \ldots \ldots \ldots \ldots \ldots \ldots \ldots \ldots \ldots \ldots \ldots \ldots \ldots \ldots \ldots \ldots
\end{aligned}
$$

である。図6は，式(7)に対応するテーパ構造である。

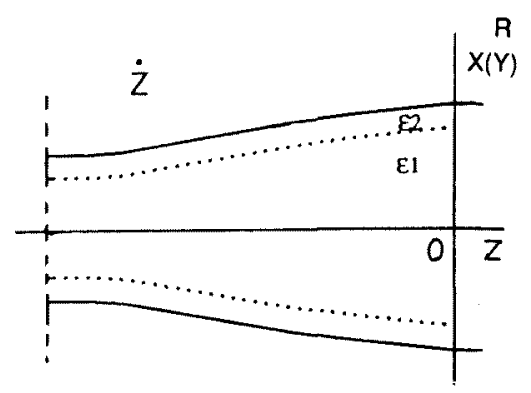

(a)

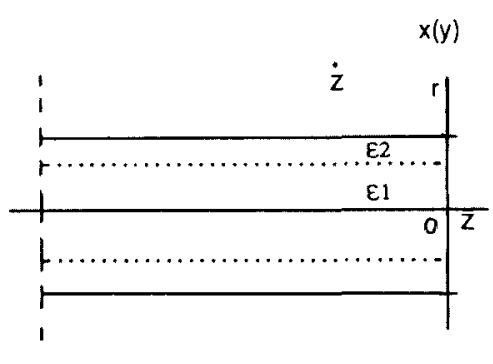

(b)

図 5.テーパ状屆折率分布型導波路における等角写像 Fig. 5 Conformal mapping for tapered waveguide of the dielectric distribution

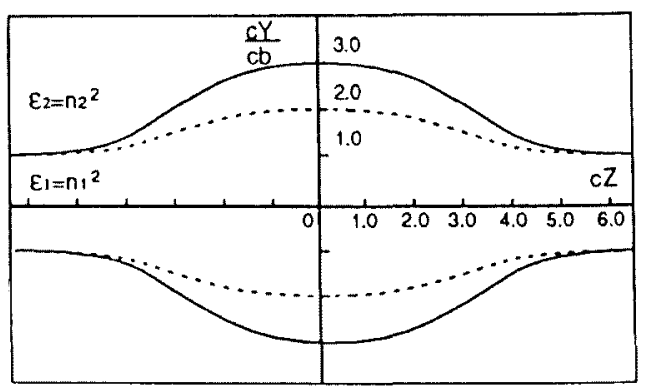

図6.テーパ導波路

Fig.6 Tapered waveguide

\section{3. テーパ型波路における電磁界}

物理空間 $(X, Y, Z)$ における導波路の電磁界 $\boldsymbol{E}_{1}, \boldsymbol{E}_{2}$ は, 二 ア部 $\Omega_{1}$, クラッド部 $\Omega_{2}$ にさ，コア部, クラッド部におけ 
る光波源を $\boldsymbol{J}_{1}, \boldsymbol{J}_{2}$ とし, 強制的電流源の位置ベクトルを $\boldsymbol{r}^{\prime}$ と LT,

$$
\begin{aligned}
& -\nabla_{x y z} \times \nabla_{x y z} \times\left(\begin{array}{c}
\boldsymbol{E}_{1}\left(\boldsymbol{R}, \boldsymbol{R}^{\prime}\right) \\
\boldsymbol{E}_{2}\left(\boldsymbol{R}, \boldsymbol{R}^{\prime}\right)
\end{array}\right)+\left(\begin{array}{c}
\beta_{1}^{2} \boldsymbol{E}_{1}\left(\boldsymbol{R}, \boldsymbol{R}^{\prime}\right) \\
\beta_{2}^{2} \boldsymbol{E}_{2}\left(\boldsymbol{R}, \boldsymbol{R}^{\prime}\right)
\end{array}\right) \\
& =-\left(\begin{array}{c}
\boldsymbol{J}_{1}\left(\boldsymbol{R}, \boldsymbol{R}^{\prime}\right) \\
\boldsymbol{J}_{2}\left(\boldsymbol{R}, \boldsymbol{R}^{\prime}\right)
\end{array}\right)
\end{aligned}
$$

ここに, 定数, $\beta_{1}, \beta_{2}$ は, $\beta_{1}^{2}=\omega^{2} \varepsilon_{1} \mu_{1}, \quad \beta_{2}^{2}=\omega^{2} \varepsilon_{2} \mu_{2}$. で ある。電磁界の境界条件は, $\partial \Omega_{1}=\partial \Omega_{2}=S$ において，

$$
\begin{aligned}
& \boldsymbol{B}\left(\begin{array}{l}
\boldsymbol{E}_{1}\left(\boldsymbol{R}, \boldsymbol{R}^{\prime}\right) \\
\boldsymbol{E}_{2}\left(\boldsymbol{R}, \boldsymbol{R}^{\prime}\right)
\end{array}\right) \\
& =\boldsymbol{n} \times\left(\begin{array}{cc}
1 & -1 \\
\nabla \times & -\nabla \times
\end{array}\right)\left(\begin{array}{l}
\boldsymbol{E}_{1}\left(\boldsymbol{R}, \boldsymbol{R}^{\prime}\right) \\
\boldsymbol{E}_{2}\left(\boldsymbol{R}, \boldsymbol{R}^{\prime}\right)
\end{array}\right)
\end{aligned}
$$$$
=0
$$

ベクトル波動方程式は， $(x, y, z)$ 空間において，まっすぐな 導波路に関する方程式として，次の非同次の方程式となる。

$$
\begin{gathered}
-\nabla_{x y z} \times \nabla_{x y z} \times\left(\begin{array}{c}
\boldsymbol{E}_{1}\left(\boldsymbol{r}, \boldsymbol{r}^{\prime}\right) \\
\boldsymbol{E}_{2}\left(\boldsymbol{r}, \boldsymbol{r}^{\prime}\right)
\end{array}\right)+\left(\begin{array}{c}
\omega^{2} \varepsilon_{1} \mu_{1} \boldsymbol{E}_{1}\left(\boldsymbol{r}, \boldsymbol{r}^{\prime}\right) \\
\omega^{2} \varepsilon_{2} \mu_{2} \boldsymbol{E}_{2}\left(\boldsymbol{r}, \boldsymbol{r}^{\prime}\right)
\end{array}\right) \\
=-\left(\begin{array}{cc}
\boldsymbol{J}_{1}\left(\boldsymbol{r}, \boldsymbol{r}^{\prime}\right)-\boldsymbol{F}\left(\boldsymbol{E}_{1}\left(\boldsymbol{r}, \boldsymbol{r}^{\prime}\right)\right) \\
\boldsymbol{J}_{2}\left(\boldsymbol{r}, \boldsymbol{r}^{\prime}\right)-\boldsymbol{F}\left(\boldsymbol{E}_{2}\left(\boldsymbol{r}, \boldsymbol{r}^{\prime}\right)\right)
\end{array}\right) \begin{array}{l}
r \in \Omega_{1}^{(0)} \\
r \in \Omega_{2}^{(0)}(20)
\end{array}
\end{gathered}
$$

境界条件は，

$$
\boldsymbol{B}\left(\begin{array}{c}
\boldsymbol{E}_{1}\left(\boldsymbol{r}, \boldsymbol{r}^{\prime}\right) \\
\boldsymbol{E}_{2}\left(\boldsymbol{r}, \boldsymbol{r}^{\prime}\right)
\end{array}\right)=0
$$

ここに， $\Omega_{1}^{(0)}$ は，導波路の内部，コア領域， $\Omega_{2}^{(0)}$ は，導波路 の外部，クラッド領域を示す。境界は，r=( $\left.X^{2}+Y^{2}\right)^{1 / 2}=$ $a$ で与えられる。ベクトル作用子項 $\boldsymbol{F}_{i}(\boldsymbol{E})$ は, 測度保数 $h_{x}, h_{y}, h_{z}$ により与えられる。軸方向の漱近解の場合には, $\frac{\partial^{2}}{\partial z^{2}}>c \frac{\partial}{\partial z}, c \frac{\partial}{\partial x}, c \frac{\partial}{\partial y}$ として,

$$
\begin{aligned}
- & \nabla_{x y z} \times \nabla_{x y z} \times \boldsymbol{E}_{i}+\omega^{2} \varepsilon_{i}^{(1)} \mu_{i} \boldsymbol{E}_{i} \\
= & -\left(1-\frac{h_{t}^{2}}{h_{3}^{2}}\right) \frac{\partial^{2} \boldsymbol{E}_{t i}}{\partial z^{2}}+\boldsymbol{J}_{i} h_{t}^{2} \\
& -\beta_{1}^{2}\left(1-h_{t}^{2}\right) \boldsymbol{E}_{t i}-\omega^{2} \varepsilon_{i}^{(2)} \mu_{i} \boldsymbol{E}_{i} \\
= & -\omega^{2} \varepsilon_{i}^{(2)} \mu_{i} \boldsymbol{E}_{i}+\boldsymbol{J}_{i} h_{t}^{2}+\boldsymbol{F}_{i}(\boldsymbol{E})
\end{aligned}
$$

$E_{t}$ は横方向ベクトル成分である。空間の歪による汎関数の 項Fは，写像されたまっすぐな導波路における媒質の不均 質と等価であるとみなされている。

方程式(22)は，関数空間における作用子表示として，次 のように示される。

$$
L E=J+L_{F} E+L_{E} E
$$

ここで, 作用子 $L, L_{F}, L_{E}$, ベクトルE, Jは,

$$
\begin{aligned}
\boldsymbol{L} & =\left(\begin{array}{cc}
\nabla_{x y z}^{2}+\omega^{2} \varepsilon_{1}^{(1)} \mu & 0 \\
0 & \nabla_{x y z}^{2}+\omega^{2} \varepsilon_{2}^{(1)} \mu
\end{array}\right) \\
\boldsymbol{L}_{F} & =-\left(\begin{array}{cc}
-\boldsymbol{F}_{1} & 0 \\
0 & -\boldsymbol{F}_{2}
\end{array}\right),
\end{aligned}
$$

$$
\begin{gathered}
\boldsymbol{L}_{E}=-\left(\begin{array}{cc}
\omega^{2} \varepsilon_{1}^{(2)} \mu & 0 \\
0 & \omega^{2} \varepsilon_{2}^{(2)} \mu
\end{array}\right) \\
\boldsymbol{E}=\left(\begin{array}{l}
\boldsymbol{E}_{1} \\
\boldsymbol{E}_{2}
\end{array}\right), \quad \boldsymbol{J}=\left(\begin{array}{l}
\boldsymbol{J}_{1} \\
\boldsymbol{J}_{2}
\end{array}\right)
\end{gathered}
$$

従って，逆作用子は， $L^{-1}=\mathcal{G}$ に対応するグリーンダイア ディックを用いれば,

$$
\boldsymbol{E}=\boldsymbol{L}^{-1} \boldsymbol{J}+\boldsymbol{L}^{-1}\left(\boldsymbol{L}_{F}+\boldsymbol{L}_{E}\right) E
$$

入射波に関する項として， $E_{0}=L^{-1} J$ とすれば， $L^{\prime}=$ $\boldsymbol{L}_{F}+\boldsymbol{L}_{E}$ として,

$$
\boldsymbol{E}=\boldsymbol{E}_{\mathrm{o}}+\boldsymbol{L}^{-1} \boldsymbol{L}^{\prime} \boldsymbol{E}_{\mathrm{o}}+\boldsymbol{L}^{-1} \boldsymbol{L}^{\prime} \boldsymbol{L}^{-1} \boldsymbol{L}^{\prime} E_{\mathrm{o}}+\cdots
$$

式(24)におけるグリーンダイアディックは, 固有界 $\phi_{\alpha}$, 固 有值 $\beta_{\alpha}$ を用いて, 正規化保数 $M_{\alpha}, M_{\beta z}$ を用いて,

$$
\begin{aligned}
G= & \sum_{\alpha} \frac{\phi_{\alpha}\left(r_{t}\right) \phi_{\alpha}^{*}\left(r_{t}^{\prime}\right)}{M_{\alpha}\left(\omega, \hat{\beta}_{z \alpha}\right)} \exp \left(-j \hat{\beta}_{z \alpha}\left|z-z^{\prime}\right|\right) \\
& +\int_{c_{\beta} u c_{\beta_{z}}} \frac{\phi_{\beta z}\left(r_{t}\right) \phi_{\beta z}^{*}\left(r_{t}^{\prime}\right)}{M_{\beta z}} \\
& \cdot \exp \left(-j \beta_{z}\left|z-z^{\prime}\right|\right) d \beta_{z} \ldots \ldots \ldots \ldots
\end{aligned}
$$

によって与えられる。コア径がスポットサイズより十分大 きく，境界の影響を無視できる不均質導波路の場合には， $\beta_{z}, \phi$ は不均質導波路のコア部の固有值により与えられる。 $\varepsilon_{1}=\varepsilon^{\prime}\left(1-\left(\left(l_{x} x\right)^{2}-\left(l_{y} y\right)^{2}\right)\right.$ のとき, 積記号】を用いて,

$$
\begin{aligned}
\boldsymbol{G}= & \sum_{m, n}\left(\boldsymbol{I}-\nabla^{\prime} \frac{1}{\omega^{2} \varepsilon_{1} \mu} \nabla\right) \frac{\exp \left(-j \beta_{m n}\left|z-z^{\prime}\right|\right)}{M_{m n}} \\
& \cdot \prod_{\substack{\xi=x, y \\
\xi \eta=m, n}} \boldsymbol{\phi}_{\xi \eta}\left(a_{\xi} \xi\right) \phi_{\xi \eta}^{*}\left(a_{\xi} \xi^{\prime}\right) \ldots \ldots \ldots \ldots \ldots
\end{aligned}
$$

$こ こ に$

$$
\begin{aligned}
M_{m n}= & j 2 \beta_{m n} \\
\beta_{m n}= & {\left[\beta_{1}^{2}-(2 n+1) l_{y} \beta_{1}\right.} \\
& \left.-(2 m+1) l_{x} \beta_{1}-g_{x} l_{x}^{2}-g_{y} l_{y}^{2}\right]^{1 / 2} \\
a_{\xi}^{2}= & \beta_{1} l_{\xi}, \quad g_{\xi}=1 \quad\left(i_{\xi} \dot{i}_{\xi}\right. \text { のきのみ) } \\
\phi_{m}\left(a_{\xi} \xi\right)= & \frac{\left(a_{\xi}^{2} / \pi\right)^{1 / 4}}{2^{m / 2} \sqrt{m_{1}}} \exp \left(-a_{\xi}^{2} \xi^{2} / 2\right) H_{m}\left(a_{\xi} \xi\right)
\end{aligned}
$$

\section{4. 接合部におけるモード変換, 結合特性}

領城 I, II, IIIをそれぞれ，入射側，テーパ部，出力側の 領域とし，それぞれの領域の誘電率を $\varepsilon^{(I)}, \varepsilon^{(I I)}, \varepsilon^{(I I I)}$, 写 像による測度俰数を $h_{i}^{(I)}, h_{i}^{(I I)}, h_{i}^{(I I I)}$ とすれば, 式(22),(25) より全電磁界は,

$$
\begin{aligned}
\boldsymbol{E}_{t o t l}= & \boldsymbol{E}_{i n c}-\sum_{s, l} \int\left[\left(1-\frac{h_{t}^{(s)^{2}}}{h_{3}^{(s)^{2}}}\right) \frac{\partial^{2}}{\partial z^{2}}\right. \\
& \left.-\omega^{2} \varepsilon_{i}^{(2)} \mu+\beta_{i}^{2}\left(1-h_{t}^{(s)^{2}}\right)\right] \boldsymbol{E}_{t} \boldsymbol{G} d v \cdots
\end{aligned}
$$


したがって，最適なテーパ屈折率分有は，式(28)に拉ける 被積分項が最小になる形状と届折率分有である。すなわ的

$$
\begin{aligned}
\sum_{s, l, t} \| & \|\left(1-\frac{h_{t}^{(s)^{2}}}{h_{3}^{(s)^{2}}}\right) \frac{\partial^{2} E_{t}}{\partial z^{2}}-\omega^{2} \varepsilon_{i}^{(2)} \mu E_{t} \\
& +\beta_{i}^{2}\left(1-h_{t}^{(s)^{2}}\right) E_{t} \| \rightarrow \min \ldots \ldots .
\end{aligned}
$$

式(29)は濑近解におけるテーパ部における最適な届折率分 布を与える関係式である。基本モードの伝搬定数を $\beta_{o z}$ と 寸れば,

$$
\sum_{s, t}\left(1-\frac{h_{t}^{(s)^{2}}}{h_{3}^{(s)^{2}}}\right)\left(-\beta_{o z}^{2}\right)+\beta_{i}^{2}\left(1-h_{t}^{(s)^{2}}\right)=\omega^{2} \varepsilon_{i}^{(2)} \mu
$$

の屆折率分布の補正が最適な屈折率分布を与える。全体の 围折率分布は，図７のように不均質分布として，

$$
\varepsilon_{i}=\varepsilon_{i}^{(1)}-\sum_{s, t}\left(1-\frac{h_{t}^{(s)^{2}}}{h_{3}^{(s)^{2}}}\right) \frac{\beta_{o z}^{2}}{\omega^{2} \mu}+\frac{\beta_{i}^{2}}{\omega^{2} \mu}\left(1-h_{t}^{(s)}\right)
$$

htは軸対称でない棛以ビーム波の変換に関倸する項である。

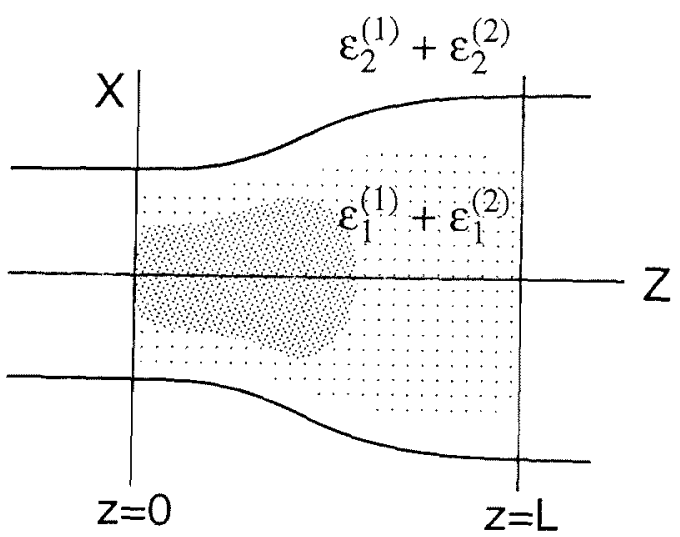

図 7. テーパ結合器と最適屈折率分布

Fig. 7 The optimum dielectric distribution for the field matching

\section{5. 円形断面テーパ部の軸対称モード変換}

円形断面をもつテーパ部に扔ける電磁界を軸対称モード 界に注目した場合には，前節とは異なる表現が可能となる。 たとえば，線素を

$$
\begin{aligned}
d s^{2} & =d R^{2}+d Z^{2}+R^{2} d \theta^{2} \\
& =h_{1}^{2} d r^{2}+h_{2}^{2} d z^{2}+R^{2} d \theta^{2} .
\end{aligned}
$$

とおけば，軸対称の電磁界は，写像空間において，Z軸か らの距踓を $R(r, z)$ とし,

$$
h=\left|\frac{d \dot{Z}}{d \dot{z}}\right|^{2}
$$

として、コア部 $(i=1)$, クラッド部 $(i=2)$, マントル部 $(i=3)$ につい,

$$
\begin{aligned}
& E_{i \theta}=\frac{\varphi_{i}}{R}, \quad H_{i r}=\frac{\left(j \omega \varepsilon_{i}-\sigma_{i}\right)}{R k_{i}^{2}} \frac{1}{h_{2}} \frac{\partial \varphi_{i}}{\partial z}, \\
& H_{i z}=\frac{\left(j \omega \varepsilon_{i}-\sigma_{i}\right)}{R k_{i}^{2}} \frac{1}{h_{1}} \frac{\partial \varphi_{i}}{\partial r}, \\
& E_{i r}=E_{i x}=0 \text {, } \\
& H_{i \theta}=\frac{\psi_{i}}{R}, \quad E_{i r}=\frac{j \omega \mu_{i}}{R k_{i}^{2}} \frac{1}{h_{2}} \frac{\partial \psi_{i}}{\partial z}, \\
& E_{i z}=\frac{j \omega \mu_{i}}{R k_{i}^{2}} \frac{\partial \psi_{i}}{\partial r} \\
& H_{i r}=H_{i z}=0
\end{aligned}
$$

$\varphi_{i}, \psi_{i}$ はつきの波動方程式を満足する。たとえば，凡偏波 の

$$
\begin{aligned}
\mathcal{L}_{R} \varphi_{i} & =\frac{\partial}{\partial r}\left(\frac{1}{R} \frac{\partial \varphi_{i}}{\partial r}\right)+\frac{\partial}{\partial z}\left(\frac{1}{R} \frac{\partial \varphi_{i}}{\partial z}\right)+\frac{h^{2}}{R} k_{i}^{2} \varphi_{i} \\
& =0 \ldots \ldots \ldots \ldots \ldots \ldots \ldots \ldots \ldots \ldots \ldots \ldots \ldots
\end{aligned}
$$

電磁界の連続性より，境界条件は，境界面 $S_{i}\left(r=r_{i}\right)$ にお いて,

$$
\begin{array}{ll}
\varphi_{i}=\varphi_{i+1}, & \frac{1}{\mu_{i}} \frac{\partial \varphi_{i}}{\partial r}=\frac{1}{\mu_{i+1}} \frac{\partial \varphi_{i+1}}{\partial r} \\
\psi_{i}=\psi_{i+1}, & \frac{1}{\varepsilon_{i}} \frac{\partial \psi_{i}}{\partial r}=\frac{1}{\varepsilon_{i+1}} \frac{\partial \psi_{i+1}}{\partial r}
\end{array}
$$

式(35)より, 測度係数, 座標に対して,

$$
\begin{aligned}
\frac{1}{R} & =\frac{1}{r}+g_{R}(r, z) \\
h^{2} & =1+f(r, z)
\end{aligned}
$$

とおけば,

$$
\begin{aligned}
\mathcal{L}_{r} \varphi_{i} & =\frac{\partial}{\partial r}\left(\frac{1}{r} \frac{\partial \varphi_{i}}{\partial r}\right)+\frac{\partial}{\partial z}\left(\frac{1}{r} \frac{\partial \varphi_{i}}{\partial z}\right)+\frac{k_{i}^{2}}{r} \varphi_{i} \\
& =-\mathcal{L}_{F} \varphi_{i} \\
\mathcal{L}_{F} & =\frac{\partial}{\partial z} g_{R} \frac{\partial}{\partial z}+f\left(\frac{1}{r}+g_{R}\right) k_{i}^{2} \cdots \cdots \cdots
\end{aligned}
$$

$\mathcal{L}_{r} \varphi_{i}=\mathcal{L}_{r}\left(r E_{\theta}\right)=0$ に対して, $\mathcal{L}_{F}$ はテーパ部の影響と見 なされる。したがって，

$$
\mathcal{L}_{\tau}\left(r E_{i \theta}\right)=\mathcal{L}_{\tau}^{0} E_{i \theta}
$$

として，式(36)の境界条件を满足するGreen 関数を $G_{i}$ とす れば

$$
\mathcal{L}_{r}^{-1}(r G)=\left(\mathcal{L}_{r}^{0}\right)^{-1} G_{i}
$$

求める電磁界は，入射波を $\varphi_{i}^{0} と し て ，$

$$
\varphi_{i}=r E_{i \theta}=\int G_{i}\left(-\mathcal{L}_{F} \varphi_{i}\right)+\varphi_{i}^{0}
$$

すなわち， $\beta_{i}$ を固有モード $\varphi_{i}^{0}$ の伝搬定数として，導波モ一 ドと放射モードの係数 $C_{i}$ を用いて, 


$$
\begin{aligned}
& G_{j}\left(\mathbf{r}, \mathbf{r}^{\prime}\right) \\
& =\sum_{i} C_{i} \varphi_{i}^{0}\left(x_{i} r\right) \varphi_{i}^{0}\left(x_{i} r^{\prime}\right) e^{-j \beta_{i}\left|z-z^{\prime}\right|} \\
& \quad+\int_{C_{\nu}} C_{\nu} \varphi_{\nu}^{0}\left(x_{\nu} r\right) \varphi_{\nu}^{0}\left(x_{\nu} r^{\prime}\right) e^{-j \beta_{\nu}\left|z-z^{\prime}\right|} d \nu \ldots .
\end{aligned}
$$

境界条件を満足する Green 関数を $G_{i}$ とすれば, 測度関数 による捸動項を $F\left(g_{R}, f\right)$ として,

$$
\begin{aligned}
E_{i, t o t l} & \\
= & \int\left(k^{2} F(s, q)\right) E_{i, t o t l} G_{i} d v \\
& -\int_{s_{0+}, s_{0-}}\left(\frac{\partial E_{i, t o t l}}{\partial n} G_{i}-\frac{\partial G_{i}}{\partial n} E_{i, t o t l}\right) d S \\
\simeq & E_{i, i n c}+\int\left(k^{2} F(s, q)\right) E_{i, t o t l} G_{i} d v \ldots \ldots \ldots
\end{aligned}
$$

式(43)の第 2 項がモード変換係数 $c_{i j}$ を与える。また, 式 (43)において, $E_{i}=\sum_{\alpha} a_{\alpha} \phi_{i, \alpha} e^{-j \beta_{\alpha} z}$ とおけば, 振幅 $a_{\alpha}$ に ついてのモード結合方程式が得られる。

$$
\frac{d \boldsymbol{a}}{d z}=\boldsymbol{K a}, \quad \boldsymbol{a}(0)=\boldsymbol{a}_{0}
$$

ここで,

$$
\begin{aligned}
\boldsymbol{a} & =\left(a_{1} a_{2} \cdots a_{n}\right)^{T}, \boldsymbol{K}=\left(c_{i j}\right), \\
\boldsymbol{a}_{0} & =\left(a_{1}^{(0)} a_{2}^{(0)} \cdots a_{n}^{(0)}\right)^{T}
\end{aligned}
$$

である。

もし, 不均質結合倸数 $K$ を, $K_{0}$ の定数ベクトルを分離し,

$$
K=K_{0}+K_{1}(z)
$$

と分解すれば，モード振幅ベクトルaは，

$$
\boldsymbol{a}(z)=e^{\boldsymbol{K}_{0} z}+\int_{0}^{z} e^{\boldsymbol{K}_{0}\left(z-z^{\prime}\right)} \boldsymbol{K}_{1}\left(z^{\prime}\right) \boldsymbol{a}\left(z^{\prime}\right) d z^{\prime} \cdots
$$

によって与えられる。モード変換は, フレドホルム型の積 分方程式の解として,

$$
\begin{aligned}
& \boldsymbol{a}(z)= e^{\boldsymbol{K}_{0} z} \boldsymbol{a}_{0} \\
&+\int_{0}^{z} e^{\boldsymbol{K}_{0}\left(z-z^{\prime}\right)} \boldsymbol{K}_{1}\left(z^{\prime}\right) \boldsymbol{a}_{0}\left(z^{\prime}\right) d z^{\prime} \\
&+\int_{0}^{z} e^{\boldsymbol{K}_{0}\left(z-z^{\prime \prime}\right)} \boldsymbol{K}_{1}\left(z^{\prime \prime}\right) \\
& \cdot \int_{0}^{z^{\prime \prime}} e^{\boldsymbol{K}_{0}\left(z^{\prime \prime}-z^{\prime}\right)} \boldsymbol{K}_{1}\left(z^{\prime}\right) \boldsymbol{a}_{0}\left(z^{\prime}\right) d z^{\prime} d z^{\prime \prime} \\
&+\cdots \\
&
\end{aligned}
$$

によって, 求められる。

\section{6. まとめ}

境界が複雑な電磁界の解析には, 等角写像と積分方程式 の混合法が有効であり, 本論文では, この混合法を実用的 にも重要な, 円形光導波路のテーパ部におけるモード変換 の検討に，適用している。とくに，軸対称のモード入射に ついての解析の基礎特性を示した。

(平成 7 年 5 月 1 日受付、同 7 年 7 月 25 日再受付)

\section{文 献}

(1) D. Marcuse: Theory of Dielectric Waveguides (Academic Press 1991).

(2) Y. Miyazaki: Optical and Quantam Electronics, vol.9, pp.153-165 (1977).

（3）宮崎保光: 電気学会雑誌, 97 巻, pp.956-963 (1977).

(4) F. Sporleder and H. G. Unger: Waveguide tapers transitions and couplers, (Peter Peregrinus LTD, 1979).

（5）沢: 信学論, 55-C 巻, 12, pp.652-660 (1972).

（6）宮崎: 電子情報通信学会論文誌, 57-C 巻, 8, pp.255-262 (1974).

（7）宮崎: 電子情報通信学会論文誌, 59-C巻, 8, pp.37-44 (1976).

（8）宇田川, 宮崎: 信学誌, 47 巻, pp.1186-1194 (1964).

（9）宇田川, 宮崎: 信学誌, 48 巻, pp.1222-1231 (1965).

(10) Y. Miyazaki: Trans. IECE. Japan, vol.59, 10, pp.1-6 (1976).

(11) Y. Miyazaki: Arch. Elekt. u. Ubertr., vol.29,pp.205211 (1975).

(12) Y. Miyazaki: Topical Meeting on Integrated Optics, USA, IEEE, Las Vegas, WA-2 (1972).

（13）宮崎: 電気学会, 電磁界理論研究会資料, EMT-91-91 (1991).

（14）宮崎: 信学会,信学技報 US92-65 (1992).

(15) Y.Miyazaki: 1994 International Symp. on EMC, Sendai, 19P406, pp.697-700 (1994).

(16) 宇田川, 宮崎: 信学誌, 49 巻, pp.2407-2416 (1966).

宮崎 保光 （正員）1941年 2 月 4 日生. 1968年 3 月名古

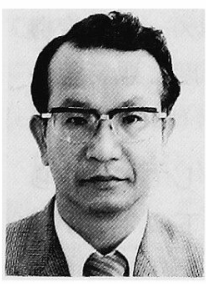

屋大学大学院工学研究科電子工学専攻博士 課程修了. 同年 4 月同大学工学部電気工学 科助手, 講師を経て, 1976 年同大学助教授. 1981 年豊橋技術科学大学工学部情報工学系 教授，現在に至る.この間，1975年〜1977 年西ドイツ・ブラウンシュバイク工科大学 高周波研究所に客員として出張. 主として, ミリ波導波路, 光ファイバ, 光集積回路, 電 磁波の散乱・回折, EMC, 生体電磁工学の研究に従事. 1970 年米沢賞受賞. 著書「応用ベクトル解析」。応用物理 学会, 電子情報通信学会, IEEE会員. 